Perfonalveränderungen im $\mathfrak{E}$. baper. Staatsforitverwaltungsdienite.

(IV. Duartal 1893.)

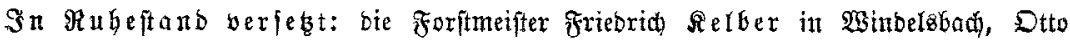

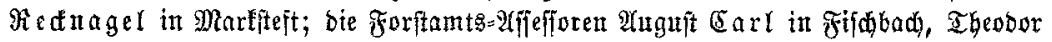
Miebermaier in 2 morbart).

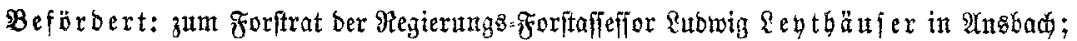
zum Regierung =Frorfteffeffor ber Forftmeifter Robert Mojer von BHingurg in

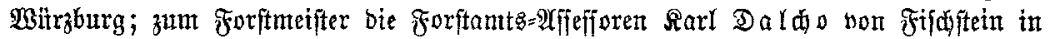

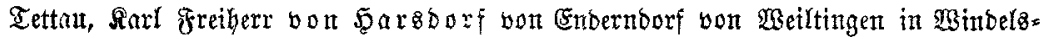
bad, Friebrid Ra/der von Burgebrad in Marftiteft, Georg Sw roll von Sllereiden

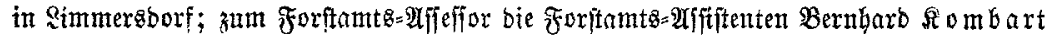

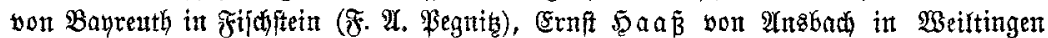

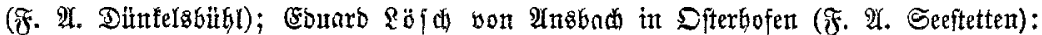

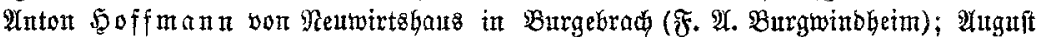

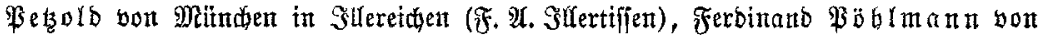

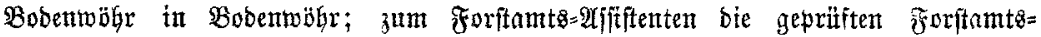

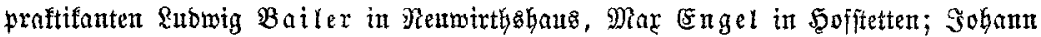
Sorban in Rangenterg; Friebrid Mantel in Eimftein-Sild, Mrfed Mebenbaber

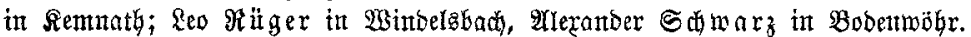

Sn gleider Dienfte seigenfwajt beriegt: bie forftmeifer c5ound Müller yon

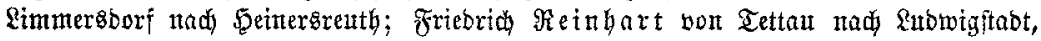

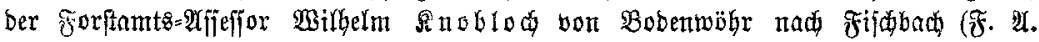

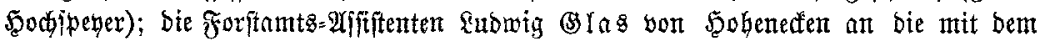
Forftamte Ranfbeuren verbuttoente Walbbanffule, Franz sienter bon EImftein = Sito

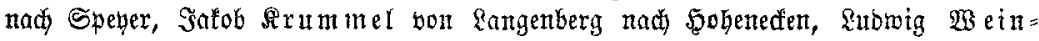
gartuter bor 5offitetten nad Ultborf.

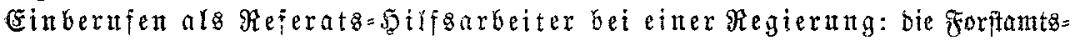

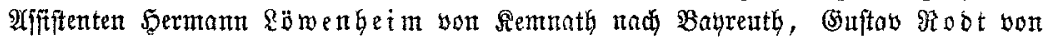

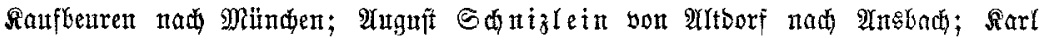
Wein von 2 sintoetgea nad 2 ngbad.

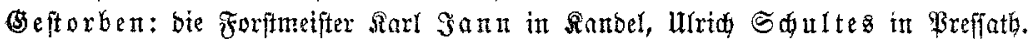

\title{
Perfonalveränderungen in Preu
}

(1. Gio 30. Noventer 1893.)

Deforiert mit bem roten Ablerorben II. Rl. mit cidenlaub unb ber

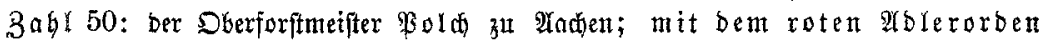

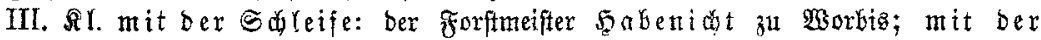
Röniglitien frone zam roten Mblerorben IV. St.: bie Forftmeifter bon

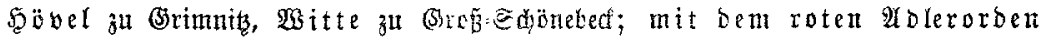

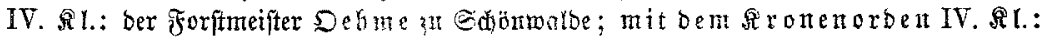

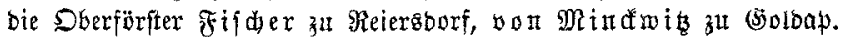

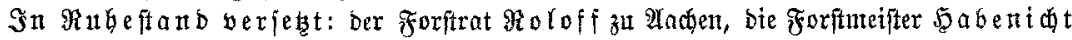
zu Worbia, Dehme zu Sø̈̈nmalbe.

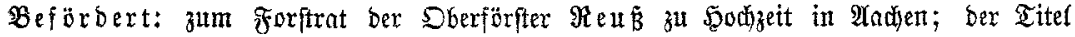

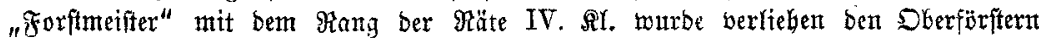

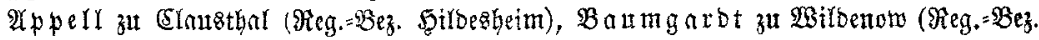

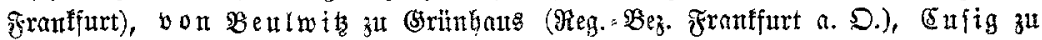

